\title{
Pioglitazone modulates the proliferation and apoptosis of vascular smooth muscle cells via peroxisome proliferators-activated receptor-gamma
}

\author{
Jing Wan ${ }^{1^{* \dagger}}$, Zhichao Xiao ${ }^{2 \dagger}$, Shengping Chao', Shixi Xiong ${ }^{1}$, Xuedong Gan ${ }^{1}$, Xuguang Qiu², Chang Xu²,
} Yexin $\mathrm{Ma}^{2}$ and $\mathrm{Xin} \mathrm{Tu}^{3}$

\begin{abstract}
Background: PPARY is a member of the nuclear hormone receptor superfamily. It has been considered as a mediator regulating metabolism, anti-inflammation, and pro-proliferation in the Vascular Smooth Muscle Cells (VSMCs).

Thiazolidinediones (TZDs), synthetic ligands of PPARY, have anti-proliferative and pro-apoptotic effects on VSMCs, which prevent the formation and progression of atherosclerosis and restenosis following percutaneous coronary intervention $(\mathrm{PCl})$. However, the underlying mechanism remains elusive. This present study therefore aimed to investigate the signaling pathway by which pioglitazone, one of TZDs, inhibits proliferation and induces apoptosis of VSMCS.

Methods: The effects of pioglitazone on VSMC proliferation and apoptosis were studied. Cell proliferation was determined using BrdU incorporation assay. Cell apoptosis was monitored with Hoechst and Annexin $V$ staining. The expression of caspases and cyclins was determined using real-time PCR and Western blot.

Results: Pioglitazone treatment and PPARY overexpression inhibited proliferation and induced apoptosis of VSMCs, whereas blocking by antagonist or silencing by siRNA of PPARY significantly attenuated pioglitazone's effect. Furthermore, pioglitazone treatment or PPARY overexpression increased caspase 3 and caspase 9 expression, and decreased the expression of cyclin B1 and cyclin D1 in VSMCs.

Conclusions: Pioglitazone inhibits VSMCs proliferation and promotes apoptosis of VSMCs through a PPARY signaling pathway. Up-regulation of caspase 3 and down-regulation of cyclins mediates pioglitazone's anti-proliferative and pro-apoptotic effects. Our results imply that pioglitazone prevents the VSMCs proliferation via modulation of caspase and cyclin signaling pathways in a PPARY-dependent manner.
\end{abstract}

Keywords: Peroxisome proliferators-activated receptor gamma, Thiazolidinedione, Apoptosis, Caspase, Cyclins

\section{Introduction}

Proliferation and apoptosis of the Vascular Smooth Muscle Cells (VSMCs) play a key role in the development and progression of the atherosclerosis and restenosis after percutaneous coronary intervention (PCI) [1,2]. Several signaling pathways are involved in the progression of atherosclerosis and restenosis and the key players

\footnotetext{
* Correspondence: wanjing320@aliyun.com

${ }^{\dagger}$ Equal contributors

'Department of Cardiology, Zhongnan Hospital of Wuhan University, Wuhan, Hubei, China

Full list of author information is available at the end of the article
}

include peroxisome proliferators-activated receptor gamma (PPAR $\gamma$ ) [3], platelet-derived growth factors (PDGF) [4], endothelin-1 (ET-1) [5], thrombin, fibroblast growth factor (FGF) [6]. Activation and interplay of these molecules induce the proliferation and migration of VSMCs, leading to formation of artery plaque. Several drugs, such as pioglitazone, a synthetic ligand of PPAR $\gamma$, have been developed to treat and prevent the proliferation of VSMCs by targeting individual factors of these pathways.

PPAR $\gamma$ is a member of the nuclear hormone receptor superfamily [7]. It has been initially considered as a mediator regulating glucose and lipid metabolism. More

\section{Ciomed Central}

(c) 2014 Wan et al.; licensee BioMed Central Ltd. This is an Open Access article distributed under the terms of the Creative Commons Attribution License (http://creativecommons.org/licenses/by/2.0), which permits unrestricted use, distribution, and reproduction in any medium, provided the original work is properly credited. The Creative Commons Public Domain Dedication waiver (http://creativecommons.org/publicdomain/zero/1.0/) applies to the data made available in this article, unless otherwise stated. 
recently, studies have revealed the presence of PPAR $\gamma$ in endothelial cells (ECs), VSMCs, macrophages and cardiomyocytes. PPAR $\gamma$ has multiple functions, including anti-inflammation and pro-proliferation in VSMCs [8]. Apoptosis is an important contributor to the formation of atherosclerosis, especially in the process of restenosis after PCI. PPAR $\gamma$ has anti-apoptotic effect herein by modulation of caspase 3 [9].

Pioglitazone is commonly used as a primary antidiabetic drug. Previous studies have shown that pioglitazone was able to inhibit the proliferation and induce apoptosis of VSMCs [10,11]. However, the underlying mechanisms have not been well understood yet. Hence, the aim of present study was to determine if pioglitazone regulates cell cycle and caspase cascades, leading to an inhibition in VSMCs proliferation.

\section{Materials and methods}

\section{Cell culture and in vitro cell treatment}

Human coronary artery smooth muscle cells (Lonza, Basel Switzerland) were grown and maintained in SmGM2 media (Lonza, Basel Switzerland) supplemented with $2 \%$ fetal calf serum, $10 \mathrm{ng} / \mathrm{mL}$ human epidermal growth factor, $1.0 \mathrm{mg} / \mathrm{ml}$ hydrocortisone, $12 \mathrm{mg} / \mathrm{mL}$ bovine brain extract, $50 \mathrm{mg} / \mathrm{mL}$ gentamicin, and $50 \mathrm{ng} / \mathrm{mL}$ amphotericin $\mathrm{B}$ at $37^{\circ} \mathrm{C}$ in $5 \% \mathrm{CO}_{2}$ atmosphere. The purity of each VSMCs preparation in culture ( $>99 \%)$ was confirmed by immunocytochemistry for $\alpha$-smooth muscle actin. VSMCs between passage 2 and 6 were used for following experiments. VSMCs $\left(1 \times 10^{6}\right)$ were treated for $24 \mathrm{~h}$ in medium containing vehicle $(0.5 \%$ methyl cellulose), $10 \mathrm{uM}$ pioglitazone or $1 \mathrm{uM}$ GW9662, (Sigma). To over-express PPAR $\gamma-1$ in VSMCs, cells were transduced with the recombinant adenovirus at titers of $100 \mathrm{MOI}$ for 24 hours. Wild type PPAR $\gamma-1$ adenovirus (Ad-wtPPAR $\gamma$ ) and mutation PPAR $\gamma-1$ adenovirus were kind gifts from Dr. Qinglin Yang (Morehouse School of Medicine, Atlanta, USA). According to the principles of siRNA design and the PPARY gene sequence (GenBank Accession No. NM_005037), the duplexes of specific siRNA sequences 5'-GTTCAAACACATCACCCCC-3' was synthesized, non targeting siRNA: 5' -GCATATTGTCTATGACCAACT-3'.

\section{Adenoviral transduction of VSMCs}

The resultant recombinant virusmids were transfected into packaging cells HEK293 to generate recombinant adenoviruses. The primary crude lysates of the recombinant adenoviruses were prepared and purified by cesium chloride gradient ultracentrifugation as viral stocks and titrated using a standard plaque assay. VSMCs were seeded at a density of $2 \times 10^{5}$ in one 6 -cm dish in antibiotic-free medium containing $10 \%$ serum before incubation with the transduction reagent Oligofectamine (Invitrogen Carlsbad, $\mathrm{CA}$ ). One day later, cells were transduced with the recombinant adenovirus at titers of $100 \mathrm{MOI}$ for 24 hours following the manufacturer's protocols. For co-transduction studies, attractene (Qiagen) was employed as the transduction agent following the manufacturer's recommendations, and non-targeting siRNA was used as experimental controls. During the final 24 hours of transfection, cells were treated with either vehicle $(0.5 \%$ methyl cellulose) or pioglitazone $(1 \mu \mathrm{M})$ [12].

\section{BrdU cell proliferation assay}

The cell proliferation assay was performed by measuring 5-Bromo-2'-deoxy-uridine (BrdU) (Roche Applied Science, USA) incorporation into the newly synthesized DNA of replicating cells. To determine cell proliferation, VSMCs were plated in 96-well plates and allowed to attach for 24 hours. Cells were then treated with $1 \mathrm{uM}$ Pioglitazone, 10 uM GW9662 or transduced with the recombinant adenovirus for 24 hours. The cells were loaded with BrdU in the last 4 hours of treatment. BrdU incorporation was quantified by an immunofluorescence assay kit (Roche Applied Science, USA) following manufacturer's instructions. Three fields were chosen randomly from various sections to ensure objectivity of sampling. Digital images were acquired using a confocal microscope. Each assay repeated three times. The total 100 cells from each field were counted, and BrdU positive cell and the ratio of BrdU positive cell versus 100 cells were calculated using a confocal microscope. Each assay repeated three times.

\section{Apoptosis of VSMCs detected by Hoechst staining}

To evaluate morphologic changes of apoptotic VSMCs, morphology and apoptosis assay were performed using the Hoechst staining as described previously [9]. Briefly, cells were seeded on chamber slides, treated with $1 \mathrm{uM}$ Pioglitazone, 10 uM GW9662 or transduced with the recombinant adenovirus for $24 \mathrm{~h}$. Cells then were washed, fixed and stained with Hoechst 33258 (Sigma, St. Louis, MO). Dead cells and apoptotic bodies were identified by condensed or fragmented nuclei using a Nikon confocal microscope. The apoptotic scores were counted from five randomly selected fields by direct counting 500 cells in each sample using a blinded method [13]. The percentage of apoptotic cells was calculated as the number of apoptotic cells divided by the number of total cells.

\section{Measurement of apoptosis by flow cytometry}

Apoptosis was measured using the FITC-Annexin V Apoptosis Detection kit (BD Bioscience, San Diego, CA) as described previously with modifications [14]. Briefly, VSMCs were harvested, incubated and treated with 10 uM GW9662, 1 uM pioglitazone or transduced with the recombinant adenovirus for $24 \mathrm{~h}$. After cell treatment, VSMCs were washed twice with cold PBS and 
resuspended in $1 \times$ binding buffer, (10 $\mathrm{mM}$ HEPES/ $\mathrm{NaOH}$, $\mathrm{pH} 7.4,140 \mathrm{mM} \mathrm{NaCl}, 2.5 \mathrm{mM} \mathrm{CaCl} 2)$ at a concentration of $1 \times 10^{6}$ cells $/ \mathrm{ml}$. Then $1 \times 10^{5}$ cells in $100 \mu$ binding buffer were transferred to $5 \mathrm{ml}$ tubes and stained with $5 \mu \mathrm{l}$ of FITC-Annexin $\mathrm{V}$ and $5 \mu$ propidium iodide (PI). The cells were gently mixed and incubated at room temperature for $15 \mathrm{~min}$. After washing the cells with $1 \times$ binding buffer to remove the excess FITC-Annexin V and PI, the cells were analyzed on a FACScan flow cytometer, which the wavelength of excitation and emission were $488 \mathrm{~nm}$ and $525 \mathrm{~nm}$, respecrively. The data were analyzed using CellQuest software.

\section{Detection of active caspases $3 / 7,8$ and 9 in VSMCs}

Caspases activities were measured using the Vybrant FAM caspase 3/7, 8 and 9 Assay Kit (Molecular Probes, Invitrogen) according to the manufacturer's recommendations after the incubation of cells with pioglitazone (1uM), GW9662 (10uM), or transduced with the recombinant adenovirus for $24 \mathrm{~h}$. The assay was performed on a fluorescent inhibitor of caspases (FLICA) methodology. The increase in the caspases activities was determined by comparing these results with the level of the untreated control. Samples analyzed on a FACScan flow cytometry with $488 \mathrm{~nm}$ excitation and green emission for the FLICA-stained cells.

\section{Western blot}

After cell treatment, VSMCs were washed with phosphatebuffered saline (PBS) and lysed in RIPA buffer (Biotech, Shanghai, China). After one freeze/thaw cycle, lysates were centrifuged. Protein concentration was determined by a BCA protein assay (Biotech, Shanghai, China) using bovine serum albumin as the standard. A quantity amounting to $10 \mu \mathrm{g}$ of protein sample was subjected to SDS-polyacrylamide gel electrophoresis. Proteins were then transferred to an ECL nitrocellulose membrane (Millipore). Incubating the membrane in Superblock (Pierce) for $1 \mathrm{~h}$ blocked nonspecific binding. Membranes were then incubated overnight at $4^{\circ} \mathrm{C}$ in primary antibodies, PPAR 1 , Cyclin D1, Cyclin B1/cdc2 and $\beta$-actin (AbCam: ab8924, ab95281, ab7959, ab1801). All primary antibodies dilution was 1:1000 in each reaction. The blots were washed three times with TBST buffer and then incubated for $1 \mathrm{~h}$ at room temperature with anti-rabbit secondary antibody conjugated with horseradish peroxidase. Western blot analysis was conducted according to standard procedures using Supersignal chemiluminescence detection substrate (Pierce).

\section{Real time RT-PCR}

Total RNA was extracted from VSMCs using TRIZOL reagent (Invitrogen, Carlsbad, CA, USA). cDNA was synthesized from $0.5 \mu \mathrm{g}$ of total RNA with superscriptor reverse transcriptase (Invitrogen, Carlsbad, CA, USA). The following specific primers were used: PPAR $\gamma$-forward: 5'-GCCCTTTACCACAGTTGATTTCTCCA-3'; PPAR $\gamma$ reverse: 5' -TATCCCCACAGACTCGGCACTCA-3'; Cyclin B1/cdc2-forward: 5' -CTGGGTCGGGAAGTCACTGG AAAC-3'; Cyclin B1/cdc2-reverse: 5'-GCAGCATCTTCT TGGGCACACA-3'; Cyclin D1-forward: 5'-AGGCGGAG GAGAACAAACAGATCA-3'; Cyclin D1-reverse: 5' -AGA GGAAGCGTGTGAGGCGGTAGTA-3'; $\beta$-actin-forward: $5^{\prime}$-TTTTGTGCCTTGATAGTTCGC-3'; $\beta$-actin- reverse: 5'-GAGTCCTTCTGACCCATACCC-3'. The real-time PCR analysis was performed using SyBR-Green mix (Applied Biosystems, Carlsbad, CA) on a 7500 Real Time PCR station (Applied Biosystems). The results for real-time PCR were calculated as ratio target gene expression (experimental/ control) and were expressed as fold change.

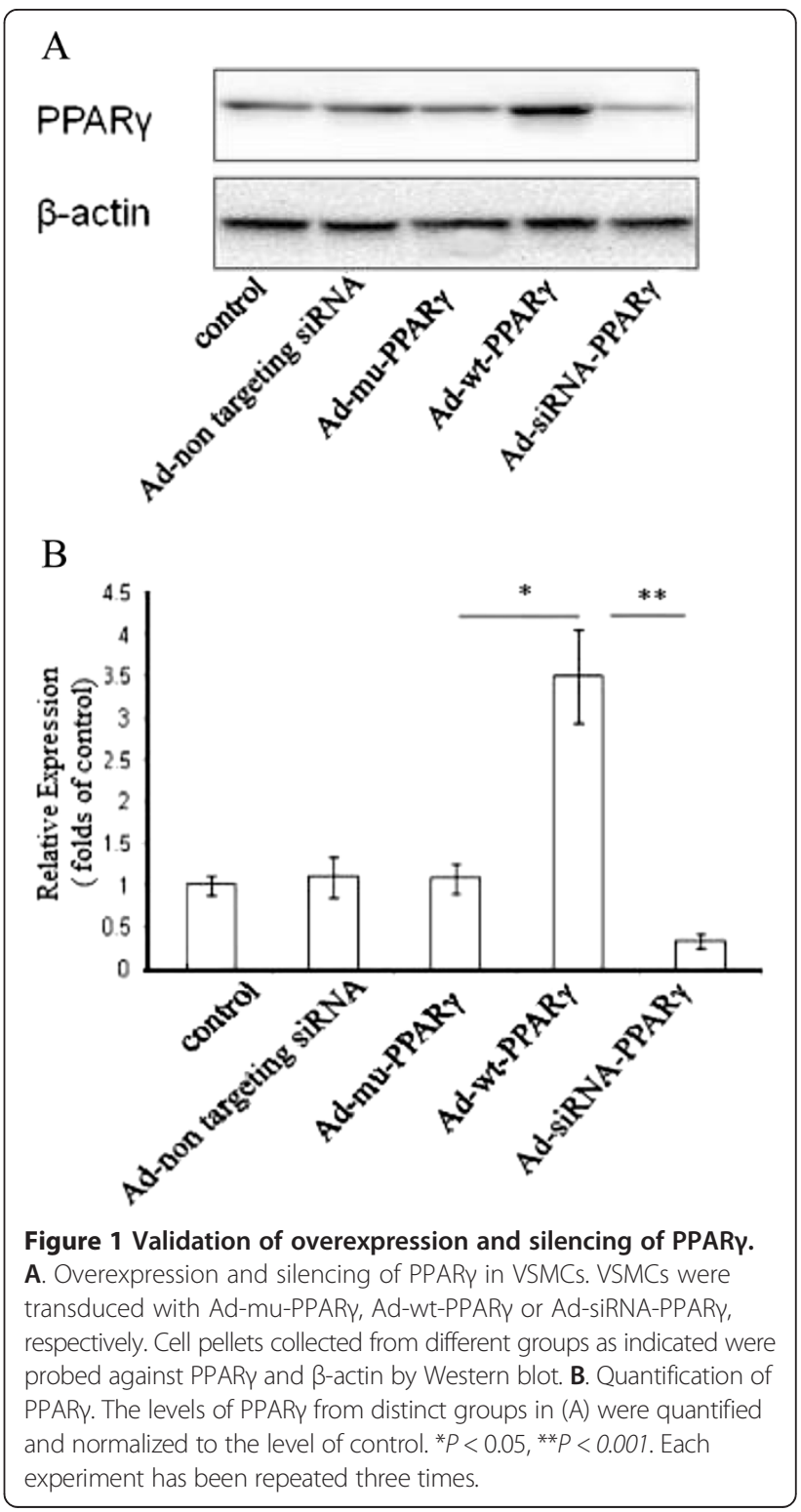




\section{Statistical analysis}

SPSS 11.0 software was used to for data analysis. Data were presented as mean \pm SEM. Student's t-test was employed to assess the statistical significance. $P<0.05$ was regarded as significant.

\section{Results}

\section{Manipulation of PPARy expression in VSMCs}

The expression levels of PPAR $\gamma$ in VSMCs were evaluated by Western blot after transduction with Adenovirus encoding wild type PPAR $\gamma$ (Ad-wt-PPAR $)$, mutant PPAR
(Ad-mu-PPAR $)$, or siRNA against PPARy (Ad-siRNAPPAR $\gamma$ ). As shown in Figure 1, PPAR $\gamma$ protein levels were significantly increased in cells transduced with Ad-wtPPAR $\gamma$ compared to Ad-mu-PPAR $\gamma(3.8 \pm 0.57$ vs. $1.09 \pm$ $0.12, P<0.05)$ (Figure $1 \mathrm{~B})$. On the other hand, silencing PPAR $\gamma$ in VSMCs has been achieved by Ad-siRNAPPAR $\gamma$ comparing with Ad-wt-PPAR $\gamma$ was $0.34 \pm 0.02$ vs. $3.8 \pm 0.57(\mathrm{P}<0.001)$, and Ad-siRNA-PPAR $\gamma$ comparing with Ad non targeting siRNA was $0.147 \pm 0.03$ vs. $0.2415 \pm$ $0.15(\mathrm{P}<0.05)$ (Figure $1 \mathrm{~B})$. The efficiency of overexpression and knockdown of PPAR $\gamma$ has been determined.
A
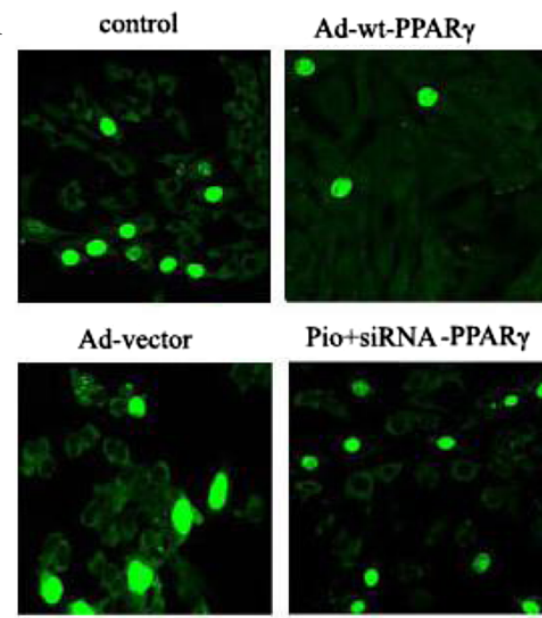

Pio + siRNA-PPAR $\gamma$
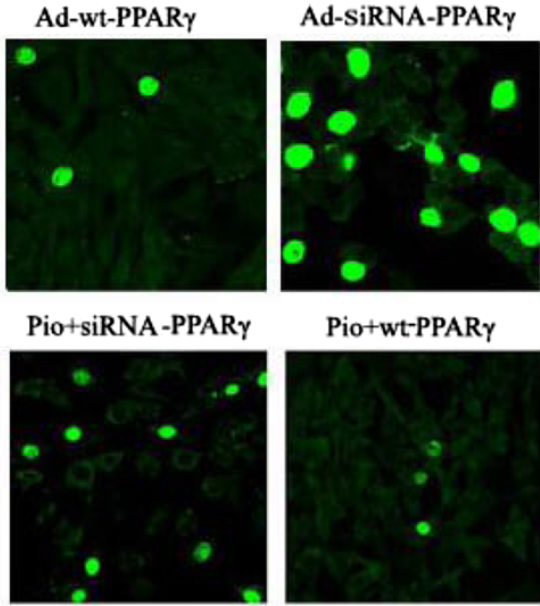

Pio+wt-PPAR $\gamma$
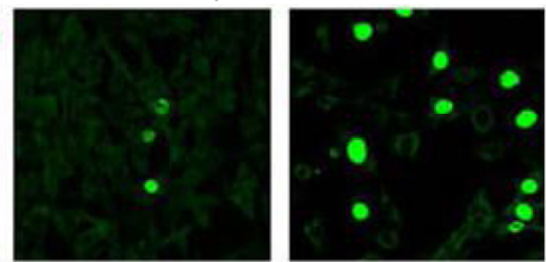

B

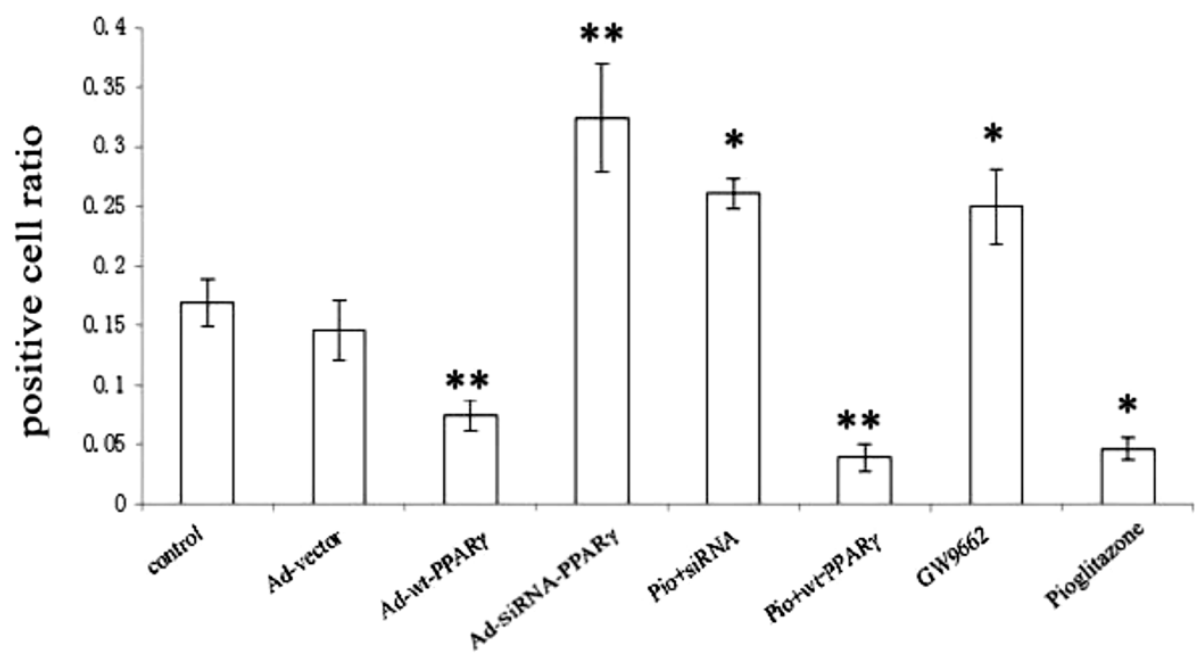

Figure 2 Pioglitazone induced proliferation of VSMC through PPARy. A. Proliferation of VSMCs is regulated by pioglitazone through PPARY signaling pathway. VSMCs alone (control), transduced with Ad-vector, Ad-wt-PPARy, or siRNA-PPARy were labeled with BrdU, respectively. In addition, VSMCs treated with pioglitazone (PIO) (1 UM), wt-PPARY-overexpressing VSMCs treated with PIO (Pio + wt-PPARY), and PPARY silenced VSMCs treated with PIO (Pio + siRNA) were harvested $24 \mathrm{~h}$ later after treatment followed by BrdU labeling. The BrdU positive VSMCs from indicated groups were recorded by confocal microscopy (600x). BrdU positive VSMCs cells from wt-PPARY, PIO + wt-PPARY, and PIO alone groups were less than those from control and vector alone groups. On the other hand, the addition of PIO in the absence of PPARY (PIO + siRNA-PPARY) and GW6992 alone induced the proliferation of VSMCs. The data is the representative of three individual experiments. B. The ratio of BrdU positive cells to total cells was quantified. The BrdU positive cell numbers and total cell numbers from each field were counted and the ratio of BrdU positive cell versus total cell numbers was calculated. ${ }^{*} P<0.01,{ }^{*} P<0.05$. Each experiment has been repeated three times. 
Pioglitazone inhibits VSMCs proliferation through PPARY signaling pathway

We initially investigated whether pioglitazone inhibits proliferation of VSMCs. VSMCs were treated with pioglitazone (PIO), and the cell proliferation was determined by BrdU assay 24 hours later. As shown in Figure 2, a significant decrease in cell proliferation was observed in the PIO treated group compared with controls $(0.051 \pm 0.01$ vs. $0.175 \pm 0.031, P<0.05)$.

We next determined if PPAR $\gamma$ pathway mediates pioglitazone's anti-proliferative effect. VSMCs were treated with GW9662, a potent antagonist of PPAR $\gamma$. GW9662 treatment significantly enhanced VSMCs proliferation $(0.248 \pm 0.054$ vs. $0.175 \pm 0.031, P<0.05)$ (Figure 2). Furthermore, PPAR $\gamma$ silenced VSMCs were treated with pioglitazone. Interestingly, PPAR $\gamma$ silencing by siRNA in VSMCs totally abolished the inhibitory effects of PIO
$(0.279 \pm 0.009$ vs. $0.051 \pm 0.01, P<0.001)$ (Figure 2). Our results indicate that anti-proliferative effect of pioglitazone is mediated by PPAR $\gamma$ signaling pathway.

\section{Pioglitazone induced apoptosis in VSMCs}

The viability of VSMCs was detected with chromatin condensation under the fluorescence microscope. Pioglitazone treatment or PPAR $\gamma$ overexpression significantly increased the numbers of condensed chromatin positive cells $(5.51 \pm 2.14 \%$ vs. $3.21 \pm 0.27 \%, P<0.01$; and $6.32 \pm 1.47 \%$ vs. $3.21 \pm 0.27 \%, P<0.001$, respectively), indicating an increase in VSMC apoptosis by pioglitazone treatment. In contrast, GW9662 and PPAR $\gamma$ silencing significantly reduced cell numbers of undergoing apoptosis $(1.67 \pm 0.15 \%$ vs. $3.21 \pm 0.27 \%, P<0.01$, and $1.17 \pm 0.16 \%$ vs. $3.21 \pm 0.27 \%, P<0.001$, respectively) (Figure 3 ).

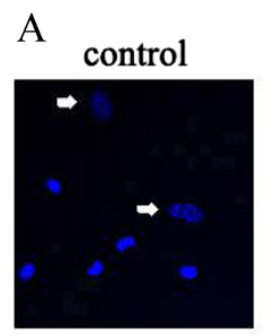

Ad-wt-PPAR $\gamma$

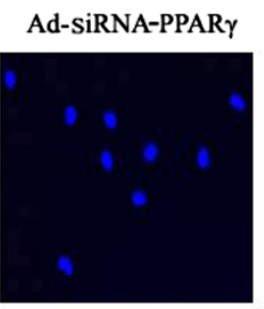

\section{Pioglitazone}
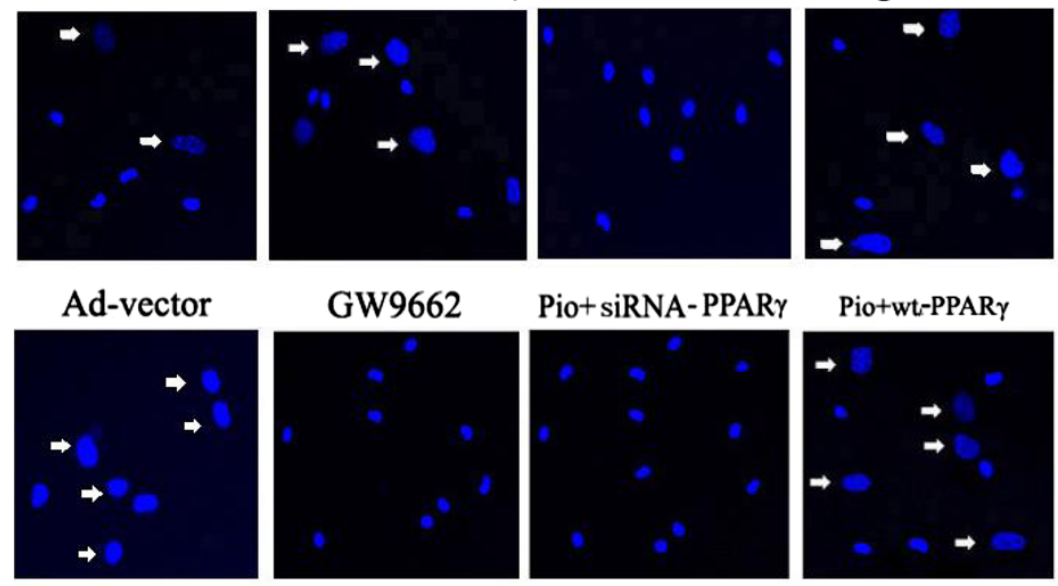

B

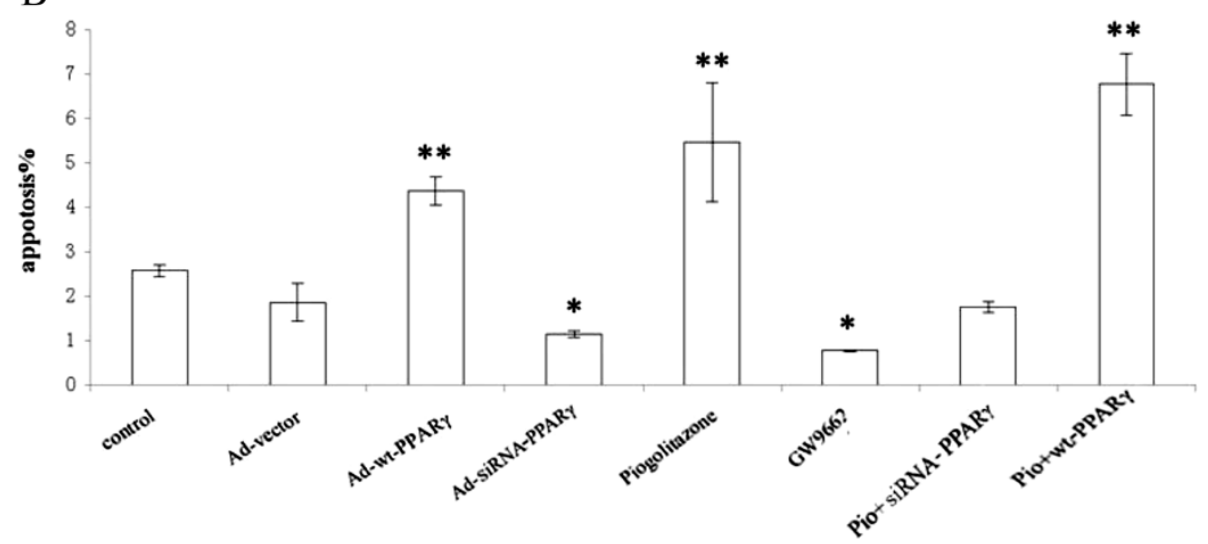

Figure 3 Induction of chromatin condensation of VSMCs by piolitazone. A. Pioglitazone induced chromatin condensation in the nuclei of VSMCs. VSMCs were seeded on top of coverslips and transfected with vector, wt-PPARY, or siRNA-PPARY, respectively. Cells (non-transduced and transduced) were then treated with different drugs as shown followed by Hoechst staining. Arrows indicate the nuclei with condensed chromatin. B. Quantification of condensed chromatin from apoptotic VSMCs. The numbers of VSMCs from different treatments were counted. The percentage of condensed-chromatin positive cells was determined. ${ }^{* *} P<0.001,{ }^{*} P<0.01$. Values are presented as the mean \pm SEM of three different fields. Each experiment has been repeated three times. 
The capability of pioglitazone to induce the apoptosis of VSMCs has been further confirmed using Annexin V staining (Figure 4). The frequency of the Annexin $\mathrm{V}^{+} / \mathrm{PI}^{-}$ cell population, which represents early apoptotic cell subset, has been indicated (Figure 4A). Pioglitazone increased apoptosis $(6.38 \pm 1.78 \%$ vs. $3.42 \pm 0.16 \%, P<$ $0.001)$ and GW9662 reduced apoptosis $(2.03 \pm 0.11 \%$ vs. $3.42 \pm 0.16 \%, P<0.01)$. Overexpression of PPAR $\gamma$ was able to induce apoptosis of VSMCs $(6.09 \pm 0.12 \%$ vs. $3.58 \pm 0.04 \%, P<0.001)$. This effect was further enhanced by the treatment of pioglitazone $(7.05 \pm 0.24$ vs. $3.58 \pm$ $0.04 \%, P<0.001)$. Silencing PPAR $\gamma$ completely blocked the induction of apoptosis mediated by Pioglitazone (Figure 4). These results suggest that pioglitazone induced VSMC apoptosis is in a PPAR $\gamma$ dependent pathway (Figure 4), which is in consistent with the results from BrdU staining (Figure 3).

\section{Pioglitazone treatment activates caspase $3 / 7$ and 8}

Activated caspase $3 / 7$ is a critical effector in the apoptosis signal pathway. Caspase 8 is a factor related to the extrinsic pathway, and caspase 9 is a key member along with intrinsic pathway. To further investigate whether activated caspases were involved in anti-proliferative effect of pioglitazone, activities of caspase3/7, 8, 9 were measured in PIO treated VSMCs. As shown in Figure 5, PIO treatment resulted in significant increases in activated caspase 3/7 $(121.67 \pm 3.06 \%)$ and caspase $8(151.2 \pm 7.03 \%)$, but not in

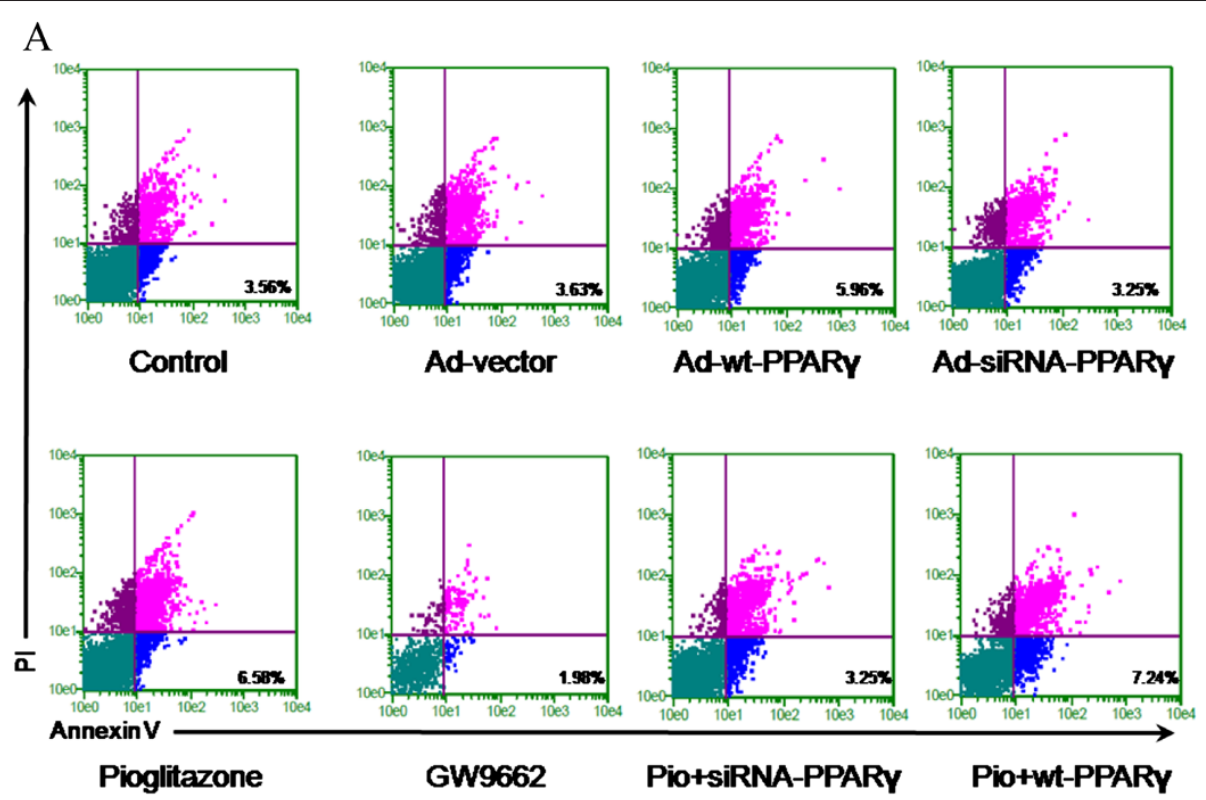

B

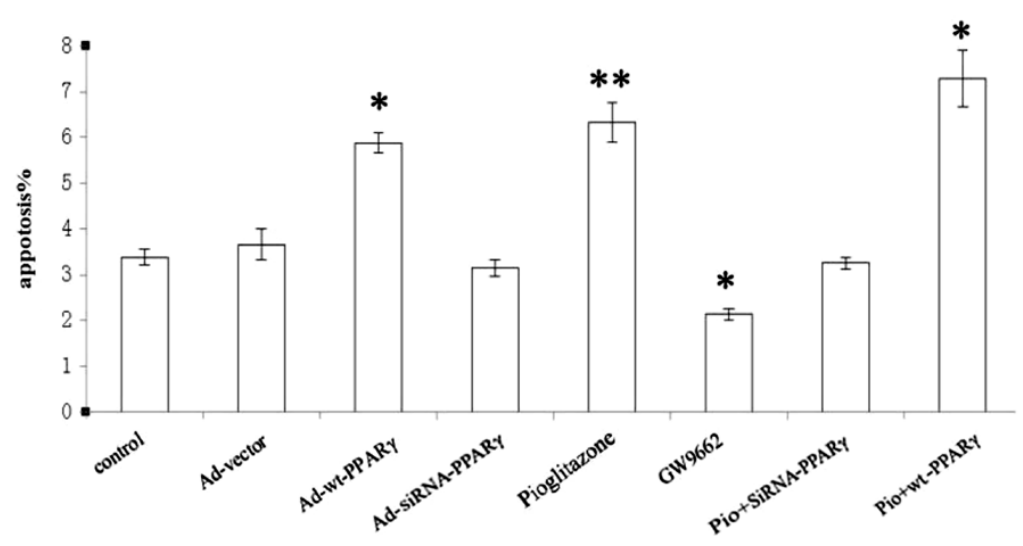

Figure 4 Pioglitazone induced apoptosis of VSMCs. A. Pioglitazone-treated VSMCs are inclined to apoptosis. Cultured VSMCs were transfected with vector, wt-PPARY, or siRNA-PPARY, respectively. Cells (non-transdued or transduced) were then treated with different drugs as indicated. VSMCs from distinct groups were then harvested and subjected to Annexin $V$ staining. The representative staining plots (A) and the frequency of apoptotic cells from three independent experiments (B) was shown. The numbers indicate the frequency of the Annexin V+/PI- cell population. Values are presented as the mean $\pm \mathrm{SEM}, \mathrm{n}=3 .{ }^{*} P<0.001,{ }^{*} P<0.01$. 


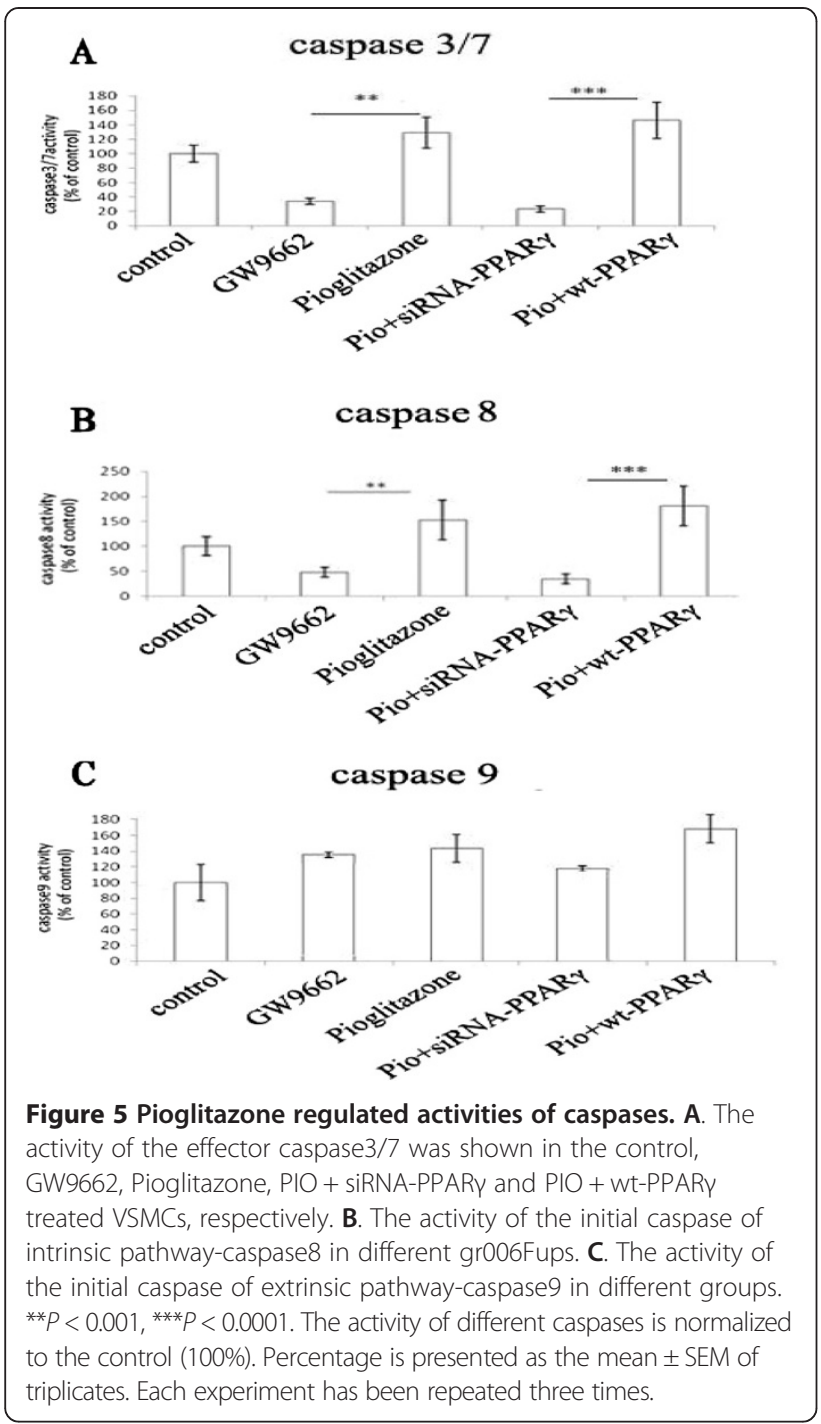

activated caspase 9. A similar effect was seen when wtPPAR $\gamma$ was overexpressed in VSMCs $(137.76 \pm 1.91 \%$, $173.56 \pm 13.12 \%)$. In contrast, GW9662 treatment resulted in significant decreases in the activation of caspase $3 / 7$ $(20.67 \pm 2.51 \%)$ and caspase $8(42.27 \pm 1.46 \%)$ (Figure 5). Silencing PPARy inhibited pioglitazone's effect on the activation of caspase $3 / 7(10.67 \pm 1.53 \%)$ and caspase 8 $(24.67 \pm 3.1 \%)$, but has no influence on caspase 9 activation (Figure 5). These results suggest that pioglitazone activates the extrinsic, not the intrinsic pathway through a PPARY dependent pathway.

\section{Effect of pioglitazone on cyclins in VSMCs}

To address the possibility that the down-regulation of cyclins in pioglitazone treated VSMCs resulted in the inhibition of cell proliferation, the effect of pioglitazone on transcription and expression levels of cyclin B1 and D1 were examined by RT-PCR and Western blot. As shown in Figure 6, pioglitazone treatment significantly down- regulated expression of cyclin B1 and cyclin D1 at both mRNA $(0.46 \pm 0.08,0.41 \pm 0.11)$ and protein $(0.75 \pm 0.12$, $0.54 \pm 0.17)$ levels. In contrast, GW9662 up-regulated the mRNA $(2.73 \pm 0.22,1.49 \pm 0.31)$ and protein $(2.18 \pm$ $0.25,3.32 \pm 0.72)$ levels of cyclin B1and cyclin D1. Moreover, PPAR $\gamma$ silencing completely abolished pioglitazone's effect. These results suggest that cyclin pathway may involve in anti-proliferative effect of pioglitazone.

\section{Discussion}

The restenosis after PCI has become one of the most concerned issues worldwide [15]. The proliferation and apoptosis of VSMCs play critical roles in this pathologic process [16]. Thus, many therapeutic treatments focused on preventing VSMC proliferation and inducing apoptosis in VSMCs. TZD is one of the most well studied agents. TZDs are synthetic ligands of PPAR $\gamma$, which is a member of the nuclear hormone receptor super-family. TZDs are primarily used as anti-diabetes drugs. TZD has also been indicated to have an anti-proliferative function in rat renal arteriolar smooth muscle cells [17]. Recently, given their anti-proliferative and pro-apoptotic effect, TZDs have been considered as novel drugs to prevent or even reverse the formation of atherosclerosis and post-PCI restenosis. Importantly, TZDs do not increase the risk of overall cardiovascular morbidity or mortality in comparison with standard glucose-lowering drugs $[18,19]$, although there was the controversy that TZDs might potentially lead to serious adverse cardiovascular effects, such as heart failure after treatment with rosiglitazone for type 2 diabetes [20-22] . However, the mechanisms by which TZDs regulate VSMC proliferation have not been determined.

Previous studies have shown that TZDs suppress the expression of inflammatory molecules, including TNF (tumor necrosis factor)- $\alpha$, MCP (monocyte chemotactic protein)-1, IL-1 $\beta$ and IL-6 in VSMCs [23,24]. Moreover, recent studies have revealed that c-fos was involved in PPARy agonists- induced growth suppression in VSMCs, and TZDs inhibited the expression of c-fos via the blockade of MAPK pathway [25]. Furthermore, Eukaryotic initiation factor 4E-binding protein (4EBP) and Src homology 2-containing inositol phosphatase 2 (SHIP2) mediate the inhibitory effects of TZD on cell growth [26]. Finally, it has been shown that TZDs prevent G1/S phase transition in PDGF or insulin stimulated VSMCs, suggesting that TZDs can induce cell cycle arrest [27].

It has been known that TZDs have anti-proliferative effect in different cell types via PI3-Kinase pathway [28]. However, whether this effect is PPAR $\gamma$-dependent remains to be clarified $[29,30]$. The effects of PPAR $\gamma$ in the vascular cells indicate its beneficial function in vascular disorders including hypertension and atherosclerosis [31]. Goetze group [29] has shown that troglitazone 


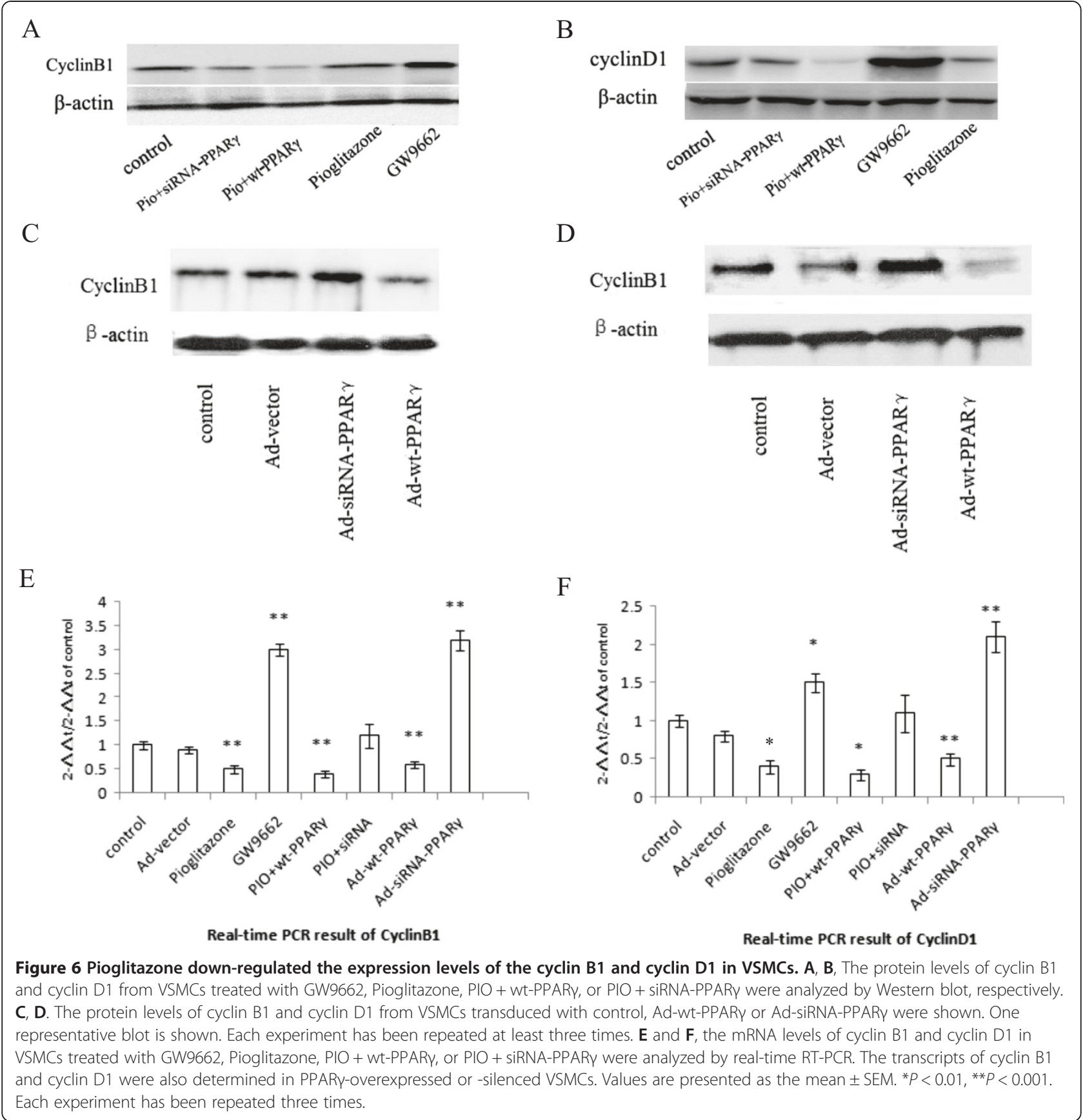

inhibited insulin-induced mitogenic signaling through a PPAR $y$-mediated inhibition of ERK-dependent phosphorylation and activation of nuclear transcription factors. However, this group revealed that TZDs activated MEK/ERK pathway through PI3-kinase and promoted c-fos mRNA expression and DNA synthesis, a process independent of PPARY pathway [30]. Cersosimo group suggested pioglitazone preserved Akt phosphorylation and attenuates MAPK signaling in insulin-stimulated VSMCs, and may play a role in arterial smooth muscle cells migration, proliferation, and inflammation in conditions of acute hyperinsulinemia [32]. In our study, we found that pioglitazone treatment and PPAR $\gamma$ overexpression inhibited VSMC proliferation. Whereas silencing PPAR $\gamma$ with siRNA attenuated the inhibitory effects. These results clearly indicate that the PPAR $\gamma$ signaling pathway is involved in anti-proliferative effect of pioglitazone. Pioglitazone is already shown to inhibit in-stent neointimal formation in humans [33].

Cyclins play critical roles in cell cycle regulation, especially cyclin B1 and cyclin D1 [34]. PPAR $\gamma$ ligands inhibited $G_{1}$ to $S$ transition by inhibiting the expression of 
minichromosome maintenance (MCM) gene, one of the downstream effector factors of pRB/E2F pathway [35]. Stimulation of PPAR $\gamma$ induced the arrest of cell cycle, accompanied by the down-regulation of cyclin $\mathrm{D}$ and cyclin B in VSMCs [36-39]. To determine the detailed mechanisms by which pioglitazone regulates VSMC proliferation, in this study the mRNA and protein levels of cyclin B1 and cyclin D1 were tested. We found that pioglitazone treatment and PAPR $\gamma$ overexpression significantly down-regulated both mRNA and protein levels of cyclin B1 and cyclin D1. These results suggest that the beneficial functions of the TZDs are mediated, at least in part, by regulating the expression and transcription of cyclin B and cyclin D.

Aside from the impact of proliferation of VSMCs on the formation of atherosclerosis and restenosis, the apoptosis of VSMC also plays an important role in these processes. The pro-apoptotic effect of PPAR $\gamma$ in VSMCs has been reported. Bruemmer's group revealed that the Oct-1 protein was regulated by the TZDs, which in turn induced overexpression of the growth arrest and DNA damage inducible protein 45(GADD45) gene, ultimately leading to the apoptosis of VSMCs [40]. Other groups have shown that pioglitazone also activated TGF (Transforming Growth Factor)- $\beta$-smad2-GADD45 pathway $[41,42]$. Pioglitazone induced apoptosis in VSMCs through Smad2 phosphorylation [11]. Caspases are a family of cysteine proteases that play important roles in apoptosis. Caspase 8 and caspase 9 are the two initiative caspases involved in both extrinsic and intrinsic apoptotic pathways, while caspase 3 is a terminal effector caspase [43]. Bruedigam group showed that rosiglitazone stimulated mineralization by induction of caspase-dependent apoptosis [44]. Here, we found that pioglitazone treatment and PPARY overexpression induced activation of caspase 8 and caspase 3/7, indicating that pioglitazone induces VSMC apoptosis through the extrinsic caspase pathway.

In summary, our study shows for the first time the regulatory pathways involved in the anti-proliferative effect of pioglitazone in VSMCs. Pioglitazone treatment inhibits proliferation of the VSMCs and induces VSMC apoptosis in a PPAR $\gamma$-dependent pathway. Down-regulation of cyclin B1 and cyclin D1 and activation of caspase 8 and caspase $3 / 7$ may be one of the mechanisms by which pioglitazone inhibits VSMC proliferation.

\footnotetext{
Abbreviations

TZDs: Thiazolidinediones; PPARy: Peroxisome proliferators-activated receptor gamma; VSMCs: Vascular smooth muscle cells; PCI: Percutaneous coronary intervention; CAD: Coronary artery disease; PDGF: Platelet-derived growth factors; ET: Endothelin; FGF: Fibroblast growth factor; IL: Interleukin; ECs: Endothelial cells; TNF: Tumor necrosis factor; MCP: Monocyte chemotactic protein; EBP: Eukaryotic initiation factor 4E-binding protein; SHIP2: Src homology 2-containing inositol phosphatase 2; GADD: Growth Arrest and DNA Damage; TGF: Transforming growth factor; PIO: Pioglitazone.
}

\section{Competing interests}

The authors declare that there are no conflicts of interest.

\section{Authors' contributions}

ZX, SC, SX and XG performed apoptosis assay of VSMCs, Western blotting and realtime-PCR of CyclinB1 and D1. XQ, CX, YM and XT supervised our experiments and the manuscript. All authors approved the final version of the manuscript.

\section{Acknowledgements}

This paper was supported by the National Natural Science Foundation of China, it is youth fund, the number is 81200220 .

\section{Author details}

${ }^{1}$ Department of Cardiology, Zhongnan Hospital of Wuhan University, Wuhan, Hubei, China. ${ }^{2}$ Department of Cardiology, Tongji Medical College of Huazhong University of Science and Technology affiliated Tongji Hospital, Wuhan, Hubei, China. ${ }^{3}$ Cardiovascular Research, Life Science and Technology College, Human Genome Research Center, Huazhong University of Science and Technology, Wuhan, Hubei, China.

Received: 19 January 2014 Accepted: 10 August 2014

Published: 19 September 2014

\section{References}

1. Zwolak RM, Adams MC, Clowes AW: Kinetics of vein graft hyperplasia: association with tangential stress. J VasC Surg 1987, 5(1):126-136.

2. Ross R: Cell biology of atherosclerosis. Annu Rev Physiol 1995, 57:791-804.

3. Dannoura A, Giraldo A, Pereira I, Gibbins JM, Dash PR, Bicknell KA, Brooks G Ibuprofen inhibits migration and proliferation of human coronary artery smooth muscle cells by inducing a differentiated phenotype: role of peroxisome proliferator-activated receptor $\gamma$. J Pharm Pharmacol 2014, 10(112):2301-2314

4. Ho HC, Chang HC, Ting CT, Kuo CY, Yang VC: Caffeic acid phenethyl ester inhibits proliferation and migration, and induces apoptosis in plateletderived growth factor-BB-stimulated human coronary smooth muscle cells. J Vasc Res 2012, 49(1):24-32

5. Kitada K, Ohkita M: Matsumura YPathological importance of the endothelin-1/ET (B) receptor system on vascular diseases. Cardiol Res Pract 2012, 1212:731-738.

6. Brisset AC, Hao H, Camenzind E, Bacchetta M, Geinoz A, Sanchez JC, Chaponnier C, Gabbiani G, Bochaton-Piallat ML: Intimal smooth muscle cells of porcine and human coronary artery express S100A4, a marker of the rhomboid phenotype in vitro. Circ Res 2007, 100(7):1055-1062.

7. Willson TM, Lambert MH, Kliewer SA: Peroxisome proliferator-activated receptor gamma and metabolic disease. Annu Rev Biochem 2001, 70:341-367.

8. Rangwala SM, Lazar MA: Peroxisome proliferator-activated receptor gamma in diabetes and metabolism. Trends Pharmacol Sci 2004, 25(6):331-336

9. Xiao Y, Yuan T, Yao W, Liao K: 3 T3-L1 adipocyte apoptosis induced by thiazolidinediones is peroxisome proliferator-activated receptor-gammadependent and mediated by the caspase-3-dependent apoptotic pathway. FEBS J 2010, 277(3):687-696

10. Yuan X, Zhang Z, Gong K, Zhao P, Qin J, Liu N: Inhibition of reactive oxygen species/extracellular signal-regulated kinases pathway by pioglitazone attenuates advanced glycation end products-induced proliferation of vascular smooth muscle cells in rats. Biol Pharm Bull 2011, 34(5):618-623.

11. Ruiz E, Redondo S, Gordillo-Moscoso A, Tejerina T: Pioglitazone induces apoptosis in human vascular smooth muscle cells from diabetic patients involving the transforming growth factor-beta/activin receptor-like kinase-4/5/7/Smad2 signaling pathway. J Pharmacol Exp Ther 2007, 321(2):431-438.

12. Tashiro K, Kawabata K, Sakurai H, Kurachi S, Sakurai F, Yamanishi K, Mizuguchi H: Efficient adenovirus vector-mediated PPAR gamma gene transfer into mouse embryoid bodies promotes adipocyte differentiation. J Gene Med 2008, 10(5):498-507.

13. Akimoto $T$, Kusano $E$, Inaba $T$, limura $O$, Takahashi $H$, Ikeda $H$, Ito $C$, Ando $Y$ Ozawa K, Asano Y: Erythropoietin regulates vascular smooth muscle cell 
apoptosis by a phosphatidylinositol 3 kinase-dependent pathway. Kidney Int 2000, 58(1):269-282.

14. Tsao PN, Su YN, Li H, Huang PH, Chien CT, Lai YL, Lee CN, Chen CA, Cheng WF, Wei SC: Overexpression of placenta growth factor contributes to the pathogenesis of pulmonary emphysema. Am J Respir Crit Care Med 2004, 169(4):505-511.

15. American Heart Association: Heart Disease and Stroke Statistics-2004 Update. Dallas, TX: American Heart Association; 2004

16. Karsch KR, Haase KK, Wehrmann M, Hassenstein S, Hanke H: Smooth muscle cell proliferation and restenosis after stand alone coronary excimer laser angioplasty. J Am Coll Cardiol 1991, 17:991-994.

17. Dubey RK, Zhang HY, Reddy SR, Boegehold MA, Kotchen TA: Pioglitazone attenuates hypertension and inhibits growth of renal arteriolar smooth muscle in rats. Am J Physiol 1993, 265(4):726-732.

18. Home PD, Phil D, Pocock SJ, Henning B-N, Ramón G, Markolf H, Jones NP, Michel K, John JV MM: Rosiglitazone Evaluated for Cardiovascular Outcomes - An Interim Analysis. N Engl J Med 2007, 357:28-38.

19. Lago RM, Singh PP, Nesto RW: Congestive heart failure and cardiovascular death in patients with prediabetes and type 2 diabetes given thiazolidinediones: a meta-analysis of randomised clinical trials N Engl J Med 2007, 356:2457-2471.

20. Home PD, Pocock SJ, Beck-Nielsen H, Curtis PS, Gomis R, Hanefeld M, Jones NP, Komajda M, McMurray JJ: Rosiglitazone evaluated for cardiovascular outcomes in oral agentcombination therapy for type 2 diabetes (RECORD): a multicentre, randomised, open-label trial.; RECORD Study Team. Lancet 2009, 373(9681):2125-2135.

21. Nissen SE, Kathy W: Effect of rosiglitazone on the risk of myocardial infarction and death from cardiovascular causes. N Engl J Med 2007, 356(24):2457-2471.

22. Sonal S, Loke YK, Furberg CD: Long-term risk of cardiovascular events with rosiglitazone, a meta-analysis. JAMA 2007, 298(10):1189-1195.

23. Park KG, Lee KM, Chang YC, Magae J, Ando K, Kim KB, Kim YN, Kim HS, Park $J Y$, Lee KU, Lee IK: The ascochlorin derivative, AS-6, inhibits TNF-alphainduced adhesion molecule and chemokine expression in rat vascular smooth muscle cells. Life Sci 2006, 80(2):120-126.

24. Takata Y, Kitami Y, Yang ZH, Nakamura M, Okura T, Hiwada K: Vascular inflammation is negatively autoregulated by interaction between CCAAT/enhancer-binding protein-delta and peroxisome proliferatoractivated receptor-gamma. Circ Res 2002, 91(5):427-433.

25. Law RE, Meehan WP, Xi XP, Graf K, Wuthrich DA, Coats W, Faxon D, Hsueh WA: Troglitazone inhibits vascular smooth muscle cell growth and intimal hyperplasia. J Clin Invest 1996, 98(8):1897-1905.

26. Benkirane K, Amiri F, Diep QN, El Mabrouk M, Schiffrin EL: PPAR-gamma inhibits ANG II-induced cell growth via SHIP2 and 4E-BP1. Am J Physiol Heart Circ Physiol 2006, 290(1):H390-H397.

27. Wakino S, Kintscher U, Kim S, Yin F, Hsueh WA, Law RE: Peroxisome proliferator-activated receptor gamma ligands inhibit retinoblastoma phosphorylation and G1 S transition in vascular smooth muscle cells. J Biol Chem 2000, 275(29):22435-22441.

28. Mishra P, Paramasivam SK, Thylur RP, Rana A, Rana B: Peroxisome proliferator-activated receptor gamma ligand-mediated apoptosis of hepatocellular carcinoma cells depends upon modulation of PI3Kinase pathway independent of Akt. J Mol Signal 2010, 5:20.

29. Goetze S, Kim S, Xi XP, Graf K, Yang DC, Fleck E, Meehan WP, Hsueh WA, Law RE: Troglitazone inhibits mitogenic signaling by insulin in vascular smooth muscle cells. J Cardiovasc Pharmacol 2000, 35(5):749-757.

30. Takeda K, Ichiki T, Tokunou T, lino N, Takeshita A: 15-Deoxy-delta 12,14prostaglandin $\mathrm{J} 2$ and thiazolidinediones activate the MEK/ERK pathway through phosphatidylinositol 3-kinase in vascular smooth muscle cells. J Biol Chem 2001, 276(52):48950-48955.

31. Duan SZ, Usher MG, Mortensen RM: Peroxisome proliferator-activated receptor-gamma-mediated effects in the vasculature. Circ Res 2008, 102(3):283-294.

32. Cersosimo $E, X u X$, Musi N: Potential role of insulin signaling on vascular smooth muscle cell migration, proliferation, and inflammation pathways. Am J Physiol Cell Physiol 2012, 302(4):652-657.

33. Takagi T, Okura H, Kobayashi Y, Kataoka T, Taguchi H, Toda I, Tamita K, Yamamuro A, Sakanoue Y, Ito A, Yanagi S, Shimeno K, Waseda K, Yamasaki M, Fitzgerald PJ, Ikeno F, Honda Y, Yoshiyama M, Yoshikawa J: A prospective, multicenter, randomized trial to a ssess efficacy of pioglitazone on in-stent neointimal suppression in type 2 diabetes:
POPPS (Prevention of In-Stent Neointimal Proliferation by Pioglitazone Study). JACC Cardiovasc Interv 2009, 2(6):524-531.

34. Morgan DO: Principles of CDK regulation. Nature 1995, 374(6518):131-134.

35. Florence G, Dennis B: Transcriptional control of vascular smooth muscle cell proliferation by peroxisome proliferator-activated receptor- $\gamma$ : therapeutic implications for cardiovascular diseases. PPAR Res 2008, 2008:429123.

36. Santucci MA, Mercatali L, Brusa G, Pattacini L, Barbieri E, Perocco P: Cell-cycle deregulation in BALB/C 3T3 cells transformed by 1,2dibromoethane and folpet pesticides. Environ Mol Mutagen 2003, 41(5):315-321.

37. Kim EJ, Park KS, Chung SY, Sheen YY, Moon DC, Song YS, Kim KS, Song S, Yun YP, Lee MK, Oh KW, Yoon DY, Hong JT: Peroxisome proliferatoractivated receptor-gamma activator 15-deoxy-Delta12,14-prostaglandin J2 inhibits neuroblastoma cell growth through induction of apoptosis: association with extracellular signal-regulated kinase signal pathway. J Pharmacol Exp Ther 2003, 307(2):505-517.

38. Strakova N, Ehrmann J, Dzubak P, Bouchal J, Kolar Z: The synthetic ligand of peroxisome proliferator-activated receptor-gamma ciglitazone affects human glioblastoma cell lines. J Pharmacol Exp Ther 2004, 309(3):1239-1247.

39. Jeon EM, Choi HC, Lee KY, Chang KC, Kang YJ: Hemin inhibits hypertensive rat vascular smooth muscle cell proliferation through regulation of cyclin D and p21. Arch Pharm Res 2009, 32(3):375-382.

40. Bruemmer D, Yin F, Liu J, Berger JP, Sakai T, Blaschke F, Fleck E, Van Herle AJ, Forman BM, Law RE: Regulation of the growth arrest and DNA damage-inducible gene 45 (GADD45) by peroxisome proliferatoractivated receptor gamma in vascular smooth muscle cells. Circ Res 2003, 93(4):e38-e47

41. Redondo S, Ruiz E, Santos-Gallego CG, Padilla E, Tejerina T: Pioglitazone induces vascular smooth muscle cell apoptosis through a peroxisome proliferator-activated receptor-gamma, transforming growth factorbeta1, and a Smad2-dependent mechanism. Diabetes 2005, 54(3):811-817.

42. Yoo J, Ghiassi M, Jirmanova L, Balliet AG, Hoffman B, Fornace AJ Jr, Liebermann DA, Bottinger EP, Roberts AB: Transforming growth factorbeta-induced apoptosis is mediated by Smad-dependent expression of GADD45b through p38 activation. J Biol Chem 2003, 278(44):43001-43007.

43. Gustafsson AB, Gottlieb RA: Bcl-2 family members and apoptosis, taken to heart. Am J Physiol Cell Physiol 2007, 292(1):C45-C51.

44. Bruedigam C, Eijken M, Koedam M, Chiba H, Van Leeuwen JP: Opposing actions of rosiglitazone and resveratrol on mineralization in human vascular smooth muscle cells. J Mol Cell Cardiol 2011, 51(5):862-871.

doi:10.1186/1758-5996-6-101

Cite this article as: Wan et al:: Pioglitazone modulates the proliferation and apoptosis of vascular smooth muscle cells via peroxisome proliferators-activated receptor-gamma. Diabetology \& Metabolic Syndrome 2014 6:101

\section{Submit your next manuscript to BioMed Central and take full advantage of:}

- Convenient online submission

- Thorough peer review

- No space constraints or color figure charges

- Immediate publication on acceptance

- Inclusion in PubMed, CAS, Scopus and Google Scholar

- Research which is freely available for redistribution 